\title{
Assessing the influence of the color of the plate on the perception of a complex food in a restaurant setting
}

\author{
Betina Piqueras-Fiszman ${ }^{1 *}$, Agnes Giboreau ${ }^{2}$ and Charles Spence ${ }^{1}$
}

\begin{abstract}
Background: Nowadays, more and more importance is given to how restaurant dishes are visually presented. With regard to the color of the plate, several recent studies have demonstrated that identical foods served on plates (or in containers) of different colors are often perceived differently at both the sensorial and hedonic levels. However, to date, these effects have not been tested in an ecologically valid setting with a range of more complex foods in order to assess the generalizability of the findings. The aims of the present study were to test the extent to which the color of the plate may influence the gustatory and hedonic experiences of a complex food. Specifically, we investigated diners' perception of three desserts served on a white or black plate in a between-participants experimental design in a real restaurant setting.
\end{abstract}

Results: The results demonstrated that the color of the plate exerted a significant influence on people's perception of the food, but that this effect varied as a function of the type of dessert served. The effects cannot be explained only in terms of color contrast. Color-flavor associations, for example, black with intense chocolate flavor, or even sophisticated chocolate, could have an impact too. Interestingly, the perceptual pattern for each dessert was constant for each plate used; that is, for all of the attributes rated, the higher scores were obtained with the same plate, for all of the desserts.

Conclusions: These results confirm the importance of the color of the plate (or background color) on people's expectation and perception of food, even in realistic and less controlled conditions, such as that of a restaurant.

Keywords: Food perception, Color influence, Flavor intensity, Liking, Consumer studies, Restaurant setting, Ecologically valid contexts, External validity

\section{Background}

Food and drink is normally consumed from certain containers/receptacles, such as plates, bowls, cups, glasses or product packaging (for example, drinks cans or plastic yoghurt pots). Great importance is often given to how the food or drink is visually presented [1-3], both in supermarkets and restaurants. Researchers are interested in examining the extent to which food and drink can be made to look more appealing and appetizing [4]. There is also interest in trying to modulate consumers' impressions of serving size and intake by modifying factors other than the food itself $[5,6]$. It is becoming increasingly clear that

\footnotetext{
* Correspondence: Betina.piqueras-fiszman@psy.ox.ac.uk

'Department of Experimental Psychology, University of Oxford, South Parks Road, Oxford OX1 3UD, UK

Full list of author information is available at the end of the article
}

our perception of food is affected not only by the various sensory properties of the food, but also by our expectations about it and other contextual factors $[7,8]$.

With regard to the influence of the appearance of food on people's perception of its flavor, it is important to note that the color of a food or beverage often dominates over other sources of information regarding the flavor [9-13].

Focusing on the culinary context, several recent studies have demonstrated that the color of the surroundings in which food is presented (for example, cups, plates, tablecloth and even ambient lighting) has an effect on both consumers' perception of the food as well as the amount that they serve themselves, and, very likely, consume. Recent studies have also provided evidence documenting the impact of the color of food containers on taste and flavor perception [14-17].

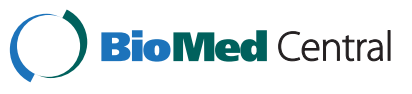

(c) 2013 Piqueras-Fiszman et al.; licensee BioMed Central Ltd. This is an Open Access article distributed under the terms of the Creative Commons Attribution License (http://creativecommons.org/licenses/by/2.0), which permits unrestricted use, distribution, and reproduction in any medium, provided the original work is properly cited. 
Regarding the effects of the color of the container on serving size, van Ittersum and Wansink [18] (study 2) found that those participants in a high color contrast condition served $9.8 \%(P<0.01)$ more than the target serving size on a larger plate, and $13.5 \%(P<0.01)$ less than the target serving size on a smaller plate. Meanwhile, in another study, van Ittersum and Wansink [18] (study 5) tested the effect of color contrast between the food and the plate on serving sizes in a realistic serving situation. Their results revealed that participants in the low color contrast condition (white pasta sauce on a white plate or red pasta sauce on a red plate) served themselves significantly $(P<0.01)$ more pasta than participants in the high color contrast condition (white pasta sauce on a red plate or red pasta sauce on a white plate). These two studies can potentially be framed in terms of the Delboeuf illusion, the name given to the illusion whereby a central circle appears smaller when surrounded by a much larger concentric circle than when surrounded by a circle that is only slightly larger $[19,20]$. It has been shown that this illusion is enhanced by color contrast, and it could therefore provide a possible explanation for why and how plate size can influence people's serving behavior in a variety of real life situations.

With regard to the contrast effect between the color of the food and the color of the plate (that is, the color of the dish, cup, and so on), there are also mechanisms that may explain the perception of certain 'illusory' or more saturated colors. For instance, the orange of a carrot is intensified if it is served on a blue (as compared to a white) plate due to the phenomenon of simultaneous contrast [21]. If the color of the plate (or background) affects the way in which people perceive the color of the food [21-23] and the color of the food is known to affect the perception of flavor, then the color of the plate (and any contrast effects that it elicits) could be expected to influence the perceived properties of the food (for example, the flavor intensity). Piqueras-Fiszman et al. [24] studied this effect under laboratory conditions in a within-participants experiment using white and black plates. The results revealed that a strawberry mousse of homogeneous color and texture tasted significantly more intense and sweeter, and was liked more, when served on a white plate as compared to when served on a black plate. However, although these results are interesting from a purely sensory/psychological perspective, they have not been tested in an ecologically valid context and with more complex foods (that is, foods varying in color, texture, and so on).

Under more realistic conditions, such as that represented by dining in a restaurant setting, diners do not try the same food served from different plates; and, in addition, diners may consume different drinks in the meantime (such as soft drinks, wine or water), consume the meal at a variable pace and converse. Consequently, less attention may be paid to elements, such as where the food is presented. Moreover, in restaurants and bars, food is not presented in exactly the same way to all of the diners, as happens in the majority of controlled laboratory studies. Therefore, the previous effects obtained might not be as evident (if present at all) when assessed in a real life situation. On the other hand, consumers are often not aware of the environmental factors that may greatly influence their food choices or consumption behaviors [25].

Many authors have already demonstrated the effects of the physical testing environment on food acceptability and choice [26-29]. In addition, a great deal of research has been carried out recently on the context effect [30-32]. While the majority of these studies have focused on the effect of the context on hedonic ratings and food choice, demonstrating in many cases that the food is liked more in a 'real life' context (although the results are not consistent across all of the studies that have been published), the focus of this study is slightly different.

The present study was designed to investigate the influence of the color of the plate on the visual and gustatory experiences of different foods, as observed in previous research [24]. However, in contrast to previous research, the study reported here was conducted in a real restaurant (and eating situation) with three different desserts (made from various elements of different colors, flavors and textures) in order to assess the extent to which the crossmodal perceptual effects found in laboratory settings can be generalized to naturalistic testing conditions. Specifically, our research questions were: Which color of plate will make each dessert seem more appetizing? Which color of plate will the color intensity of the desserts appear enhanced? Will the perception of certain sensory attributes (for example, flavor intensity) be affected by the visual perception (for example, color intensity)? Will flavorliking ratings be affected by the appearance-liking ratings? Additionally, will there be a consistent pattern of results between the different color of plates used, and between the visual and taste-related attributes assessed?

\section{Results}

All of the diners ate nearly all of the food served, and all diners finished the dessert (as reported by the restaurant manager). This information helps to match the conditions across participants.

\section{The effect of the color of the plate on pre-tasting attributes \\ Appetizing rating}

The color of the plate exerted a significant effect on consumers' appetizing appraisal of the desserts $(P<0.0001)$, and the interaction between the color of the plate and 
the dessert was also significant $(P<0.0001)$. This effect was only observed for Dessert A, which was perceived as significantly more appetizing when served on the white plate as compared to the black plate (mean $(\mathrm{M})=7.7$ versus 5.0, $P<0.0001)$. As shown in Figure $1 \mathrm{~A}$, Dessert $\mathrm{C}$ was also perceived as more appetizing when served on the white plate (although the difference was small, $\mathrm{M}=7.4$ versus 6.8), while Dessert B was rated as slightly more appetizing on the black plate $(\mathrm{M}=6.8$ versus 7.5 , on the white and black plate, respectively). In addition, the interaction of the meal session with the color of the plate was also significant $(P<0.0001)$. Diners rated the desserts served on the white plate for the lunch sessions as more appetizing (across the desserts, $M=7.6$ versus 5.8, $P<0.001$ ), while for dinner, diners rated the desserts as similarly appetizing, regardless of the color of the plate (Figure 1B).

\section{Liking of the overall presentation rating}

Perhaps unsurprisingly, the results of liking of the overall presentation ratings followed exactly the same pattern as the appetizing ratings. According to the results of the analysis of variance (ANOVA), the dessert and the color of the plate exerted a significant effect on consumers' liking ratings of the overall presentation of the dish $(P<0.0001$ and $P<0.01$, respectively). However, this effect was not observed for all the desserts, as indicated by the significant interaction between the plate and the type of dessert $(P<0.0001)$. In fact, only Dessert A was liked significantly more when served on the white plate than on the black plate $(\mathrm{M}=6.9$ versus $4.7, P<0.0001$; Figure $2 \mathrm{~A})$. The results also highlighted a tendency for Dessert $C$ to be liked more on the white plate ( $M=7.3$ versus 6.8$)$, whereas the opposite results were observed for Dessert B $(\mathrm{M}=5.2$ versus 6.9); although these latter two differences between plate colors were not significant.

Regarding the meal session, its interaction with the color of the plate was significant $(P<0.001)$. For dinner, the appearance of the dessert was similarly liked when served on either plate $(M=6.7$ versus 6.8$)$, while for lunch, serving the dessert on a white plate had a positive impact on consumers' liking of the presentation $(M=7.3$ versus 5.9, $P<0.001$; Figure 2B). However, this was not the case for all of the desserts, as suggested by the interaction between the color of the plate and the type of dessert $(P<0.0001)$.

\section{Color intensity rating}

Regarding the perceived color intensity of the desserts, significant effects were observed for the color of the plates, the type of dessert and their interaction $(P<0.05$, $P<0.001$ and $P<0.01$, respectively). In general, taking the three desserts as a group, their color was perceived as more intense when served on the white plate $(\mathrm{M}=$ 6.6 versus 6.0 ). However, at an individual level, the intensity of the color of the desserts was not significantly different when any of the desserts were served on either the white or black plate, although for Dessert $\mathrm{C}$ this difference reached marginal levels of significance $(M=7.4$ on the white plate versus 6.5 on the black plate, $P=$ 0.54; Figure 3A). Regarding the meal session, although it was not a significant factor (nor was its interaction with any other factors), the previous pattern of results observed in the other ratings was still observed (interaction with the dessert, $P=0.06$ ), suggesting that the color intensity of the desserts (A and C) was enhanced on the white plate, only for the lunch session $(\mathrm{M}=6.7$ versus 5.7, $P=0.055$; Figure 3B).
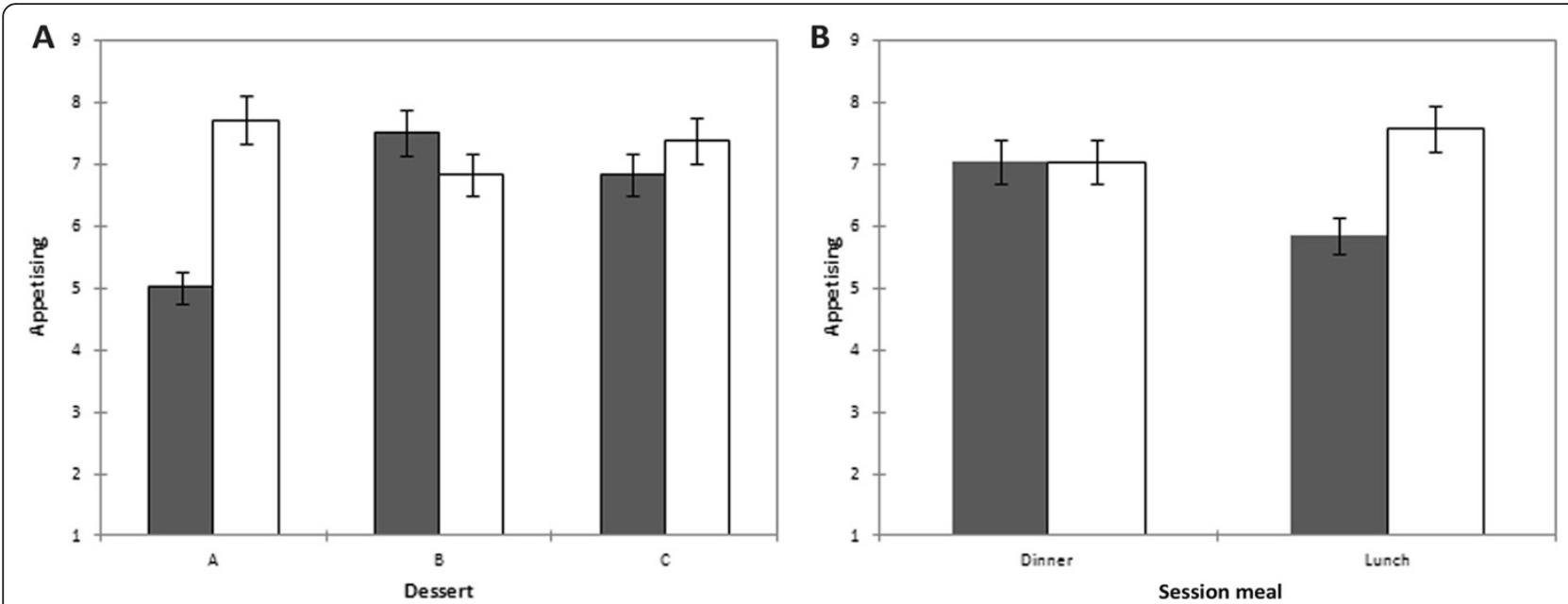

Figure 1 ANOVA results for the appetizing ratings of the dessert. (A) Interaction between the color of the plate and the dessert. (B) Interaction between the color of the plate and the meal session. White bars, ratings for the white plate condition; black bars, ratings for the black plate condition. All attributes rated on 9-point scales. Error bars represent 95\% confidence intervals. ANOVA, analysis of variance. 

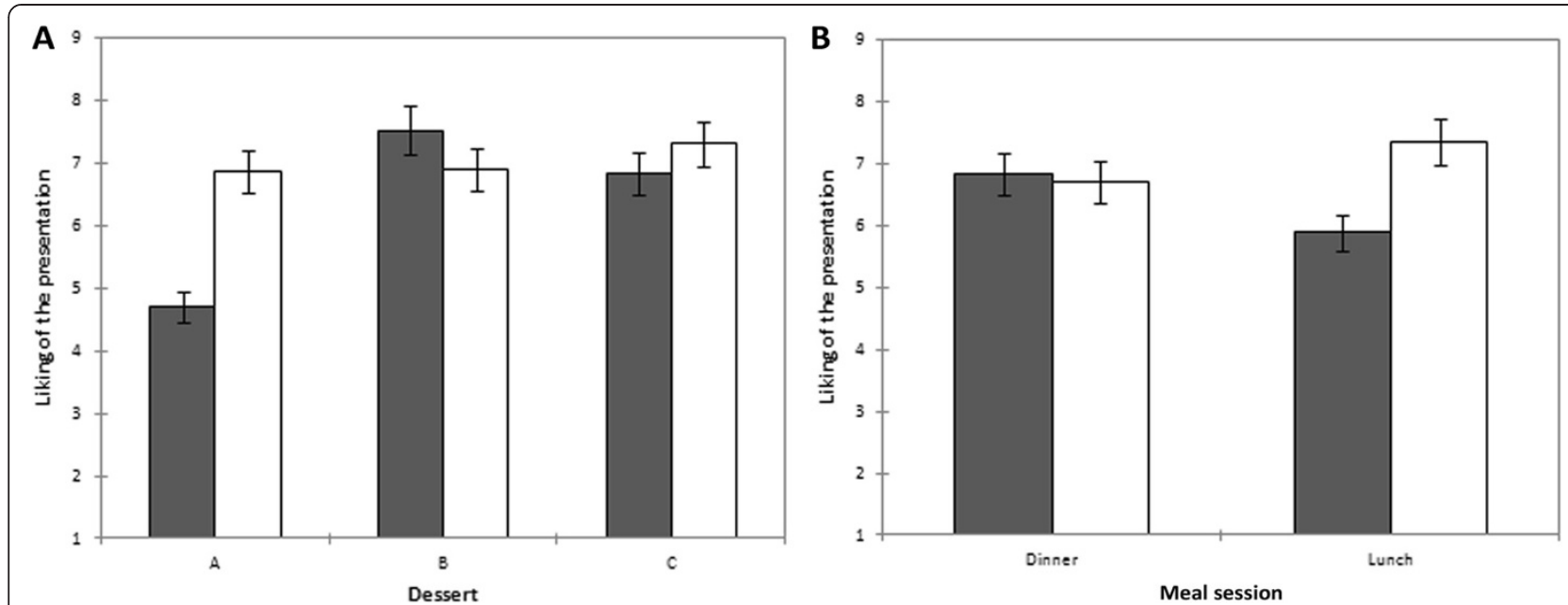

Figure 2 ANOVA results for the liking of the presentation of the dessert. (A) Interaction between the color of the plate and the dessert. (B) Interaction between the color of the plate and the meal session. White bars, ratings for the white plate condition; black bars, ratings for the black plate condition. All attributes rated on 9-point scales. Error bars represent 95\% confidence intervals. ANOVA, analysis of variance.

The effect of color of the plate on sensory attributes

The results presented so far demonstrate an effect of the color of the plate on the attributes, which were mainly based on the appearance of the presentation of the desserts (prior to tasting). The following section describes the effect of the color of the plate on the oral perception of the dessert.

\section{Flavor intensity}

The flavor intensity results were similar to the results for visual attributes, but no main effects of the color of the plate were observed. The flavor intensity was only affected by the type of dessert and its interaction with the color of the plate $(P<0.001$ and $P<0.01$, respectively). Only the flavor of Dessert B (the dessert with darker brown-colored tones, which presented less of a contrast with the black plate) was perceived as nearly significantly more intense $(6.5$ versus $7.3, P=0.08)$ when presented on the black plate (Figure 4). This suggests that the results cannot be explained by a possible contrast effect, but rather by other factors. It could be the case that presenting this dessert on a black background elicited associations with stronger intensity products (for example, chocolate/coffee products with dark-brown or black packaging are usually associated with a stronger flavor or a more sophisticated chocolate/coffee product).
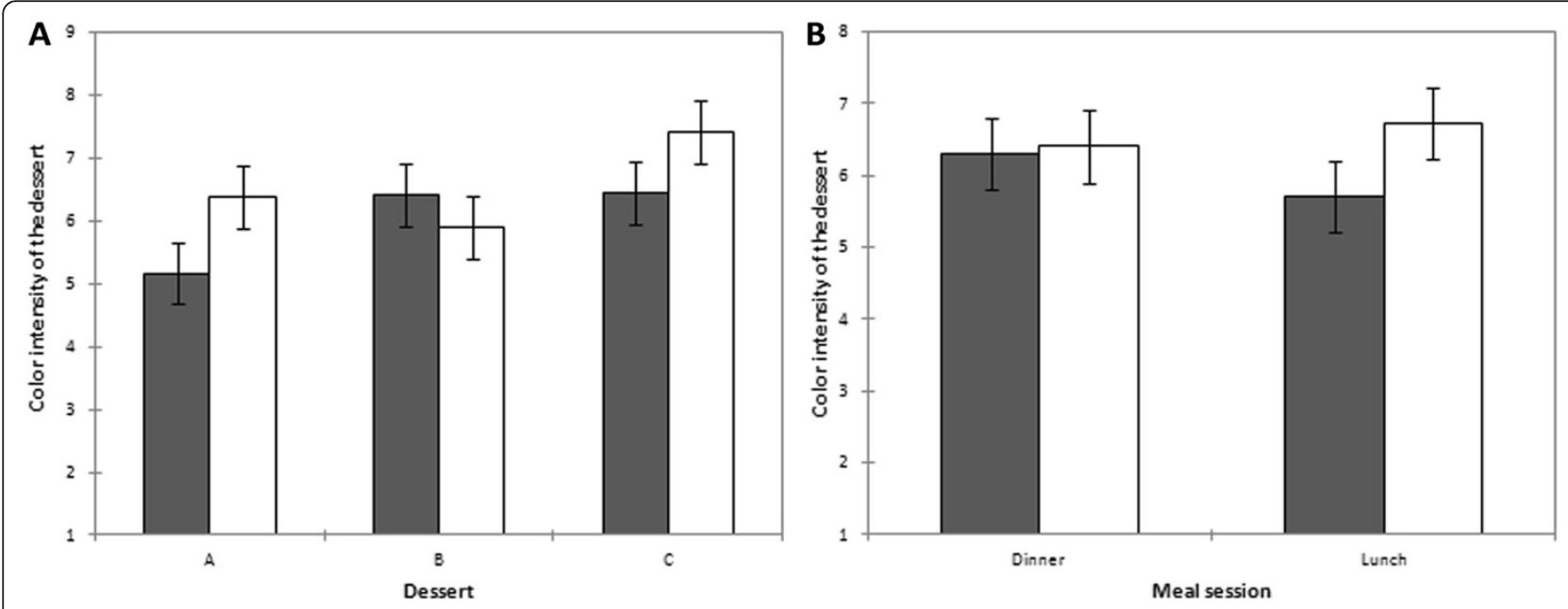

Figure 3 ANOVA results for the color intensity of the dessert. (A) Interaction between the color of the plate and the dessert. (B) Interaction between the color of the plate and the meal session. White bars, ratings for the white plate condition; black bars, ratings for the black plate condition. All attributes rated on 9-point scales. Error bars represent 95\% confidence intervals. ANOVA, analysis of variance. 


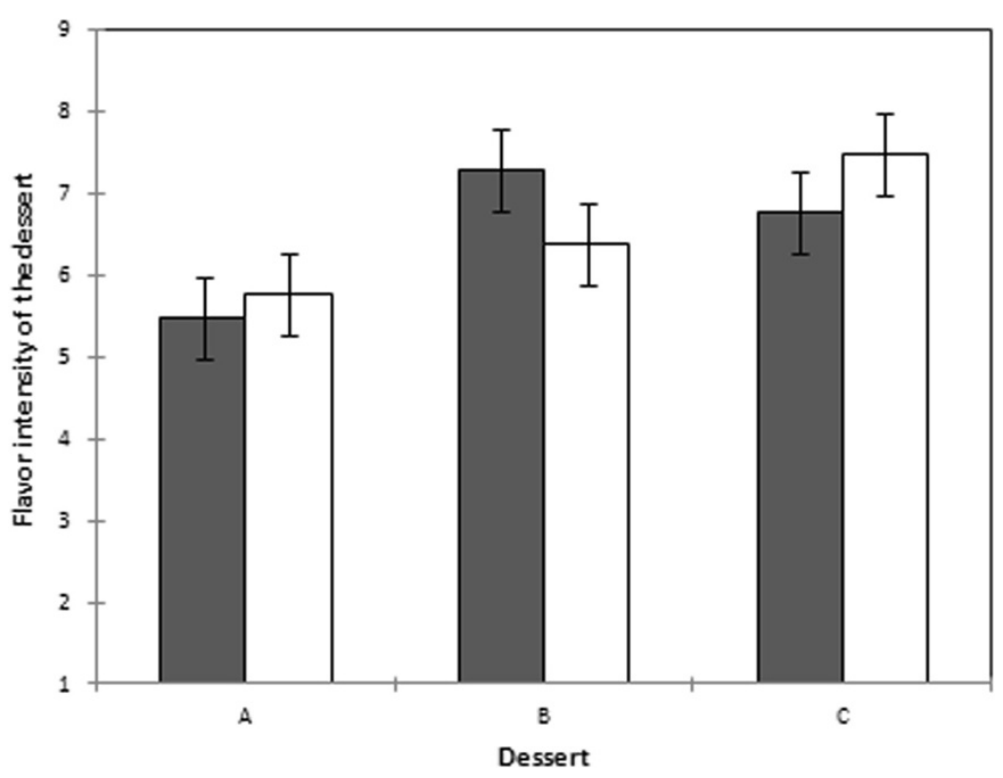

Figure 4 ANOVA results for the flavor intensity of the dessert. Interaction between the color of the plate and the dessert. White bars, ratings for the white plate condition; black bars, ratings for the black plate condition. All attributes rated on 9-point scales. Error bars represent $95 \%$ confidence intervals. ANOVA, analysis of variance.

\section{Sweetness intensity}

The type of dessert was the only attribute to have a significant effect on the perceived sweetness $(P<0.0001)$, which meant that Dessert B was rated as sweeter than Desserts $A$ and $C$, regardless of the color of the plate they were served on (Figure 5). On average, Dessert B was rated slightly ( 0.5 point) sweeter when served on the black plate than the white plate, and the opposite was observed for the other two desserts.

It is interesting to highlight that the pattern of results was maintained. The sweetness intensity of Dessert B scored higher on the black plate, and the contrary was observed for Desserts A and C, for all the attributes, even if not reaching significant levels. When the regression results

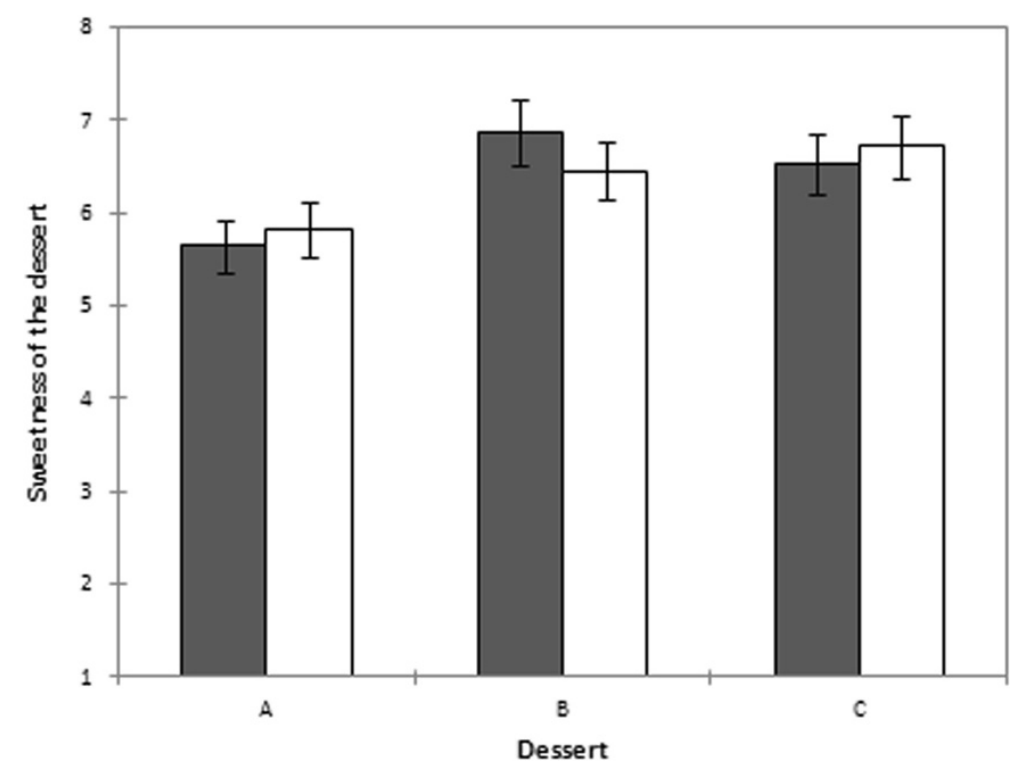

Figure 5 ANOVA results for the sweetness intensity of the dessert. Interaction between the color of the plate and the dessert. White bars, ratings for the white plate condition; black bars, ratings for the black plate condition. All attributes rated on 9-point scales. Error bars represent $95 \%$ confidence intervals. ANOVA, analysis of variance. 
between the reported color intensity, flavor intensity and sweetness intensity of the desserts were examined (Table 1), the participants' ratings of color intensity were highly correlated to the results reported for flavor intensity (for the white and black plates, $\mathrm{R}=0.539, \mathrm{r}^{2}=0.36$ and $\mathrm{R}=0.603$, $\mathrm{r}^{2}=0.29$, respectively) but not to the sweetness ratings, as the low correlation coefficients indicate $\left(\mathrm{R}=0.272, \mathrm{r}^{2}=\right.$ 0.07 and $\mathrm{R}=0.238, \mathrm{r}^{2}=0.06$, respectively). Therefore, it could be argued that when the participants perceived the color of the dessert as more intense, their perception of the flavor of the food served was also altered in a similar manner. However, as described earlier, the perceived (or reported) color intensity also varied as a function of the type of dessert, indicating that the observed correlations also depended on which dessert was served on which plate.

\section{Overall liking}

Regarding the overall liking, which was assessed after tasting the dessert, only the interaction effect between the color of the plate and the dessert was significant. Figure 6 reveals that Desserts $A$ and $C$ resulted in very similar scores for both plates, while essentially the reverse pattern was obtained for Dessert B. The latter was liked significantly more on the black plate than on the white plate $(M=7.6$ versus $6.5, P<0.05)$ and marginal differences were observed for Dessert $C$, which was liked slightly more on the white plate $(\mathrm{M}=7.6$ versus $6.8, P=0.09)$.

The effect that the hedonic attributes rated visually (that is, appetizing and liking of the presentation) on the final overall liking were highly positively correlated, as would be expected (Table 2). The regression results highlight that the participants' ratings of the final overall liking were highly correlated with the results reported for appetizing ratings (for the white and black plates, $\mathrm{R}=0.483, \mathrm{r}^{2}=0.23$ and $\mathrm{R}=0.649, \mathrm{r}^{2}=0.42$, respectively) and for liking of the presentation $\left(\mathrm{R}=0.524, \mathrm{r}^{2}=0.27\right.$ and $\mathrm{R}=0.472, \mathrm{r}^{2}=0.23$, respectively). However, depending on the dessert, the results differed to a great extent. Figures 1 and 2 (left panels) show that the ratings given to Dessert A (on a white and black plate) differed significantly for both appetizing and liking of the presentation, while the only dessert which was perceived significantly different in terms of its overall liking from one plate to the other was Dessert B. Therefore, while a correlation was observed, it cannot be entirely explained in terms of a halo effect in the ratings (Figure 6).

Table 1 Correlations (Pearson coefficient) between reported color intensity, flavor intensity and sweetness intensity, by color of plate

\begin{tabular}{lll}
\hline Plate color & Flavor intensity & Sweetness intensity \\
\hline Black & $0.603^{\mathrm{b}}$ & $0.205^{\mathrm{a}}$ \\
White & $0.539^{\mathrm{b}}$ & $0.272^{\mathrm{a}}$ \\
\hline
\end{tabular}

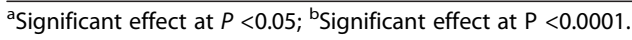

\section{Discussion}

The present study was designed to investigate whether or not the color (either black or white) of the plate would exert a significant influence on how appealing and appetizing three different desserts were rated (prior to consumption), and if the perception of these visual attributes affected the perceived flavor, sweetness intensity and final overall liking of diners in a restaurant setting. While other researchers have focused on the impact of visual cues and the presentation of food on consumers' acceptance and preference $[1,2,7]$, including the estimation of portion size [18], to date the effect of an extrinsic factor, such as the color of the plate on visual and oral perception of food, has not been studied in any depth [24]. Importantly, this study was performed in an entirely ecologically valid setting (a real restaurant), under natural conditions (that is, using a between-participants design, with participants able to interact and consume their meal at their own pace) and with three different desserts (served in as similar a manner as possible).

The results demonstrate that the color of the plate affected consumers' perception mainly for the attributes based on visual judgments (liking of the presentation, appetizing and color intensity of the dessert). One limitation to be taken into account when interpreting the results is that although the ratings given for the visual attributes were positively correlated, it could be that there was a halo effect (that is, ratings of appetizing may have overridden ratings of the color intensity and overall liking of the presentation). Although balancing the order of presentation of these attributes in the questionnaire could have ruled out this order effect, it is likely that the diners would have rated these three related attributes in a similar way, regardless of the order of presentation of the questionnaire items.

The attributes of the desserts based on chemosensory qualities of the food stimuli (that is, flavor intensity and sweetness) were affected mainly by the type of dessert served, but the extent to which these attributes were affected depended on the plate (background color) as well. Figures 2-6 demonstrate that Desserts A and $C$ always received higher scores when presented on the white plate, while the opposite was observed for Dessert B. This consistency across the attributes suggests that, by itself, the color of the plate has the potential to elicit a positive appraisal, and even enhance certain sensory qualities of foods. However, this effect depends to a great extent on the food presented, together with many other parameters, such as the context, material of the plate, and congruity between these factors and the food itself $[7,31]$. Once again, the similarity in the response patterns among the attributes could have been due to a halo effect between the attributes rated. 


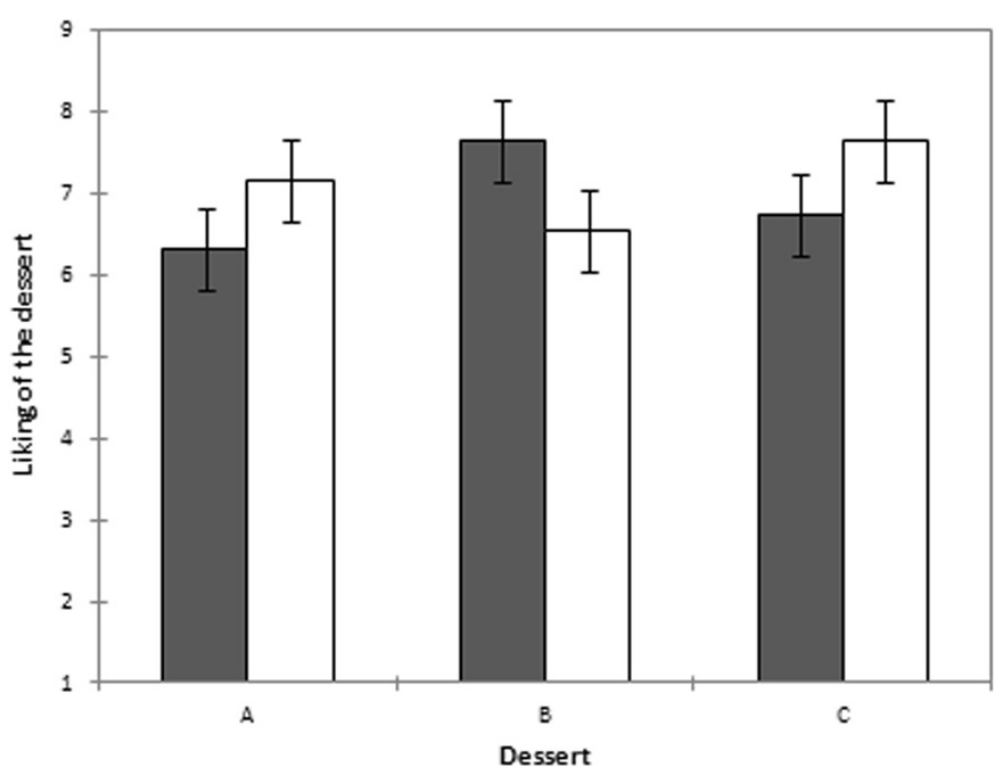

Figure 6 ANOVA results for the overall final liking of the desserts. Interaction between the color of the plate and the dessert. White bars, ratings for the white plate condition; black bars, ratings for the black plate condition. All attributes rated on 9-point scales. Error bars represent $95 \%$ confidence intervals. ANOVA, analysis of variance.

In this study, given the complexity of the visual appearance of the desserts (that is, with layers and decorations of different colors and tastes), the results cannot be explained solely in terms of color contrast between the dessert and the plate, since it was Dessert B, the dessert with darker brown-colored tones, that received higher scores when served on the black plate. This result highlights the complex reasons why consumers prefer certain food products and even perceive some attributes as enhanced when served from one container, or background, rather than another [17]. The reason for the Dessert B result could be that the black background elicited a more intense flavor (that is, it evoked this expectation), which resulted in higher attractiveness and appetizing ratings. However, flavor intensity was not significantly affected.

However, the relationship between the visual and tasterelated attributes is of greater interest. Regarding color perception, the flavor intensity patterns observed for all the desserts (Figure 4) were similar to the perceived color intensity of the desserts (Figure 3), and the two attributes were highly correlated. Certain sensory dimensions (such as intensity) are processed by several different modalities.

Table 2 Correlations (Pearson coefficient) between reported ratings of appetizing, liking of the presentation (pre-tasting attributes) and final overall liking

\begin{tabular}{lll}
\hline Plate color & Appetizing & Liking of the presentation \\
\hline Black & $0.649^{\mathrm{a}}$ & $0.472^{\mathrm{a}}$ \\
White & $0.483^{\mathrm{a}}$ & $0.524^{\mathrm{a}}$ \\
\hline
\end{tabular}

${ }^{\mathrm{a}}$ Significant effect at $\mathrm{P}<0.0001$.
Therefore, it would not be surprising if consumers implicitly perceived a food product as more intense when its color(s) is perceived as such [33].

However, it could be that the desserts simply 'looked' better to diners when served on a certain colored plate. Thus, as part of a halo effect, the rest of the ratings (sensory and hedonic) may also have been enhanced [34]. In any case, it has already been widely demonstrated that the visual appearance of food (presented in a certain container, as it usually reaches the consumer or diner) can affect both sensory discriminative and hedonic appraisal $[8,17,35]$, whether as part of a halo effect or as a genuine perceptual effect.

Regarding the lunch and dinner sessions, the lunch sessions had natural lighting conditions, while artificial lighting was used for the dinner sessions. These are the usual conditions in which diners eat at a restaurant; therefore, we decided to keep them as natural and realistic as possible. It is important to highlight that the effect of the session (only interaction effects with the color of the plate and only in ratings of visual attributes, as described in Results) could be due to the differences in illumination conditions (note that the order of presentation of the plates was counterbalanced between the sessions).

The results regarding the changes in the sensory attributes of the desserts as a function of the plate color are not as strong as reported in the Piqueras-Fiszman et al. study [24]. This is understandable, since in the context of a real restaurant, the stimuli cannot be perfectly matched for all consumers and the conditions for all of the diners cannot be kept identical (that is, diners may or may not 


\begin{tabular}{|c|c|c|c|c|}
\hline Week & & Wed & Thurs & Friday \\
\hline \multirow{2}{*}{1} & Lunch & -- & White & Black \\
\hline & Dinner & White & Black & White \\
\hline \multirow{2}{*}{2} & Lunch & -- & Black & White \\
\hline & Dinner & Black & White & Black \\
\hline \multicolumn{5}{|c|}{ Dessert A Dessert B Dessert C } \\
\hline $\begin{array}{l}\text { Figure } 7 \\
\text { fraisier, De } \\
\text { consisted }\end{array}$ & $\begin{array}{l}\text { tline of } t \\
\text { it B was a } \\
\text { a vacherin }\end{array}$ & $\begin{array}{l}\text { e 2-week s } \\
\text { raicheur of } \\
\text { lacé with }\end{array}$ & $\begin{array}{l}\text { proced } \\
\text { erry and } \\
\text { raspber }\end{array}$ & $\begin{array}{l}\text { Dessert A was a } \\
\text { la, and Dessert C } \\
\text { d basil. }\end{array}$ \\
\hline
\end{tabular}

drink while eating, certain diners may eat more rapidly than others, diners may be distracted while eating, and so on) [30]. Consequently, this makes observations hard to analyze and interpret because testing conditions cannot be controlled as strictly as in laboratory conditions and there could be many other intervening factors [36,37]. In addition, diners engaged in conversation are less likely to pay attention to the presentation of a food (in particular, to the plate). These observations contrast with testing under laboratory conditions, where participants are tested individually and are more focused on the task. However, on the other hand, these results are more ecologically valid and although no generalization can be put forward to suggest which background color is better in terms of flavor for a given food (dessert), the results nevertheless highlight that the color of the plate can exert a significant impact on consumers' expectations and appraisal of the food, prior and after consumption, despite the complex uncontrolled conditions, which makes obtaining significant results even more challenging.

Therefore, the results could be particularly relevant in situations where plated dishes are presented to diners prior to tasting, such as restaurant websites, social media, food events, pictorial menus and buffets.

\section{Conclusions}

The present study showed that the color of the plate affected consumers' perception mainly for the attributes based on visual appraisal (liking the presentation of the dish, how appetizing the dessert looked and the color intensity of the dessert). The attributes of the desserts, such as the flavor and sweetness intensity, were affected mainly by the type of dessert served, but the extent to which these attributes were affected depended on the plate (background color) as well. Some of the results can be explained in terms of color contrast; however, the associations that consumers can hold for certain colors and flavors (regarding the intensity dimension) can play an important role too. Therefore, these findings contribute to the emerging literature on how extrinsic variables can influence food perception, highlighting that the impact is dependent on the specific food evaluated and that results in real life conditions can be slightly diminished as compared to laboratory conditions. Certainly, more research is needed to confirm the validity and robustness of such results. Nevertheless, chefs can capitalize on these findings and further exploit the characteristics of the plates in order to discover potential new ways to systematically enhance expectations, perception and experience of food, apart from modifying the ingredients and decoration of the food, and mostly in situations where the plated food is showcased in advance prior to consumption.

\section{Methods}

The study was carried out at the experimental restaurant of the Institut Paul Bocuse, Lyon, France, which works as a fully operational restaurant (that is, people book, dine and pay for their meals). Three different desserts were served either on white or black plates according to the balanced between-participants experimental design shown in Figure 7. Each dessert was prepared on a different day of the week (Wednesday, Thursday or Friday), while presented on a white or black plate either during the lunch or dinner services, balanced across 2 weeks from 6 June 2012 to 15 June 2012.

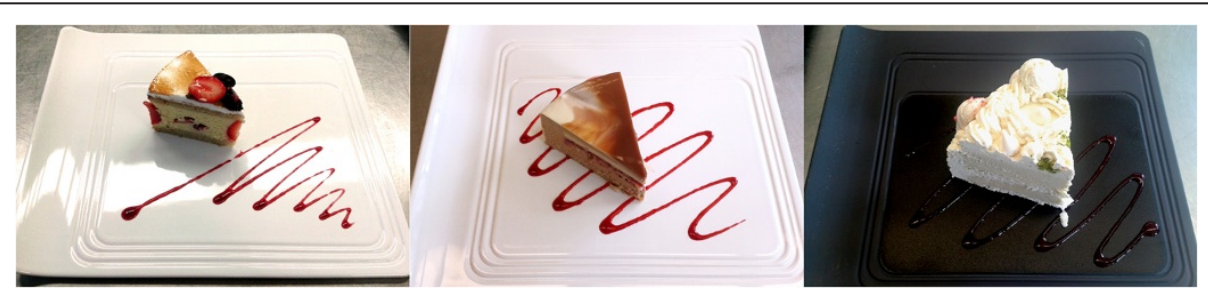

Figure 8 The three desserts. From left to right: Dessert A (fraisier), Dessert B (fraicheur of raspberry and vanilla) and Dessert C (vacherin glacé with vanilla, raspberry and basil), presented on white or black plates. 
Table 3 Participant information by day and session

\begin{tabular}{llll}
\hline Session & $\begin{array}{l}\text { Wednesday } \\
\text { (males/females) }\end{array}$ & $\begin{array}{l}\text { Thursday } \\
\text { (males/females) }\end{array}$ & $\begin{array}{l}\text { Friday } \\
\text { (males/females) }\end{array}$ \\
\hline Lunch & N/A & $19 / 32$ & $18 / 34$ \\
Dinner & $22 / 26$ & $25 / 25$ & $27 / 25$ \\
Total (n) & $48(22 / 26)$ & $101(44 / 57)$ & $104(45 / 59)$ \\
$\begin{array}{l}\text { Age } \\
\text { (years) }\end{array}$ & Mean $=45 ;$ SD $=12$ & Mean $=42 ; S D=13$ & Mean $=44 ; S D=16$ \\
\hline
\end{tabular}

\section{Food stimuli}

The dessert part of the meal was chosen as the stimulus for this study, since it is normally served in a portion and is therefore easier to ensure that diners consume it in the same manner, compared to other courses comprised of several different elements. There was flexibility in terms of the choice of dessert used (that is, we could discuss and decide with the chefs the types of desserts). Berry-based desserts were chosen, since they were reasonably consistent with the Piqueras-Fiszman et al. study [24] and were served as part of the menu in the weeks when the study was conducted (Figure 7). Dessert A was a fraisier (main colors: yellow, white and red), Dessert B was a fraicheur of raspberry and vanilla (main colors: light brown, white and red), and Dessert C consisted of a vacherin glacé with vanilla, raspberry and basil (main colors light pink, white and cream) (Figure 8). Importantly, although ideally the desserts should have been presented (and decorated) identically, this was practically impossible to control in this realistic setting. Therefore, they were served in as similar a manner as possible. In addition, a closed fixed course menu (no possibility to choose) was kept constant throughout the 2 weeks in which the study was conducted in order to rule out any bias that could have been introduced by different dishes tasted before the desserts. The courses served prior to the desserts were presented on an assortment of tableware, that is, some starters were served in a transparent bowl, while some main courses were served on a slate plate or a traditional white plate (but were kept constant and the same for all the diners).

\section{Plates}

White and black plates were ordered especially for use in this study, since they are the most commonly used colors in restaurant settings, as observed from several tableware catalogues for restaurants and hospitality. The plates were of the same shape and size (rectangular, $30 \times$ $26 \mathrm{~cm}$ ), but the white plate had a glossy finish, while the black plate had a matt finish. Although, strictly-speaking, black and white are not considered as colors, they will be referred to as such for ease of exposition here.

\section{Participants}

A total of 253 diners participated in the study and nearly all of them were French. Of these participants, 142 (56\%) were female $(\mathrm{M}$ age $=43.4$ years; $\mathrm{SD}=13.8$ years $)$. No particular recruitment process was followed. The participants simply consisted of people who had chosen to book a table for lunch or dinner at the restaurant, and taking part in the study was completely voluntary. Detailed information concerning the participants' age and gender distribution by day and session is shown in Table 3.

\section{Procedure}

The participants were welcomed to the experimental restaurant (Figure 9) and it was explained to them that a quick questionnaire would be delivered at the end of the

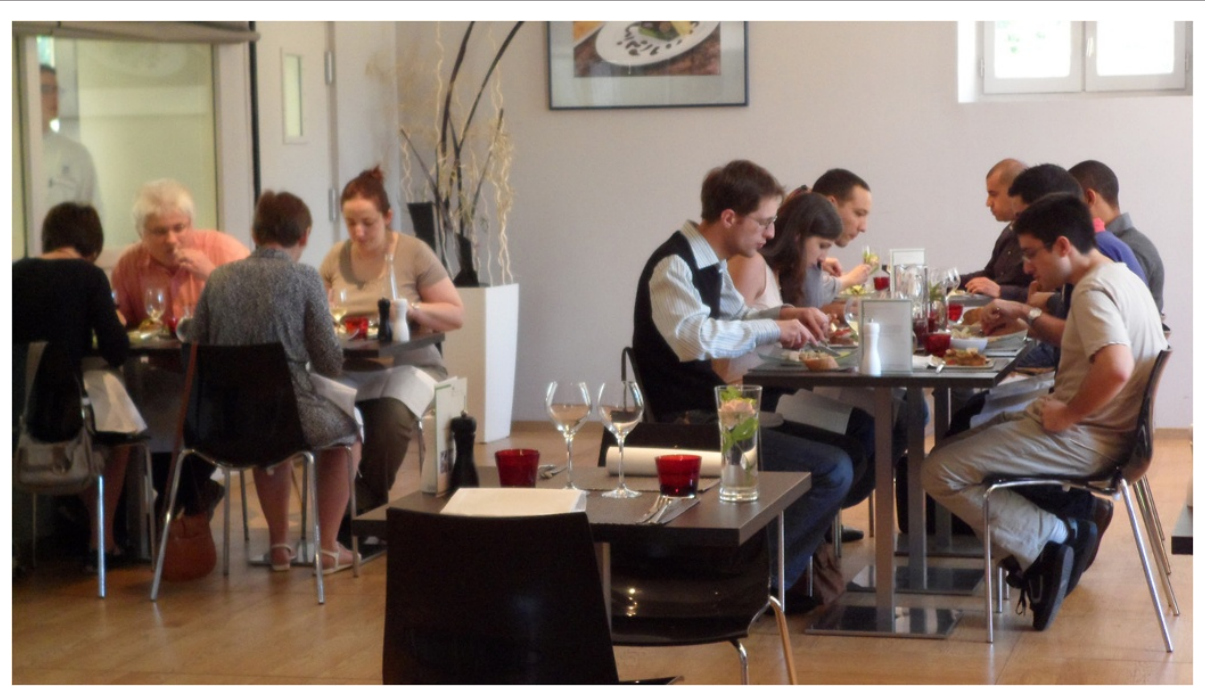

Figure 9 Experimental restaurant. 
meal in order to know what they thought about the dessert. This was worded so that the participants would most likely consider that the aim of the study was to give feedback to the trainee chefs. Participants were asked to read the questionnaire first and then proceed with the dessert. A5-size pencil-and-paper questionnaires and pens were delivered with the dessert.

In order to examine whether the color of the plate influenced the liking of the presentation and how appetizing the desserts appeared, the following questions were asked: 1) 'How appetizing is the dessert?' (visually); and 2) 'How much do you like the appearance of the dish overall?'. Since desserts with different colors as stimuli make it complex to test any possible contrast effect, a question regarding the diners' perception of the intensity of the color of the dessert was included: 3) 'How intense is the color of the dessert?'. Then, in order to check whether the appearance attributes were related to gustatory perception, once participants had tasted the dessert, questions were asked about the intensity of the flavor (overall) and of sweetness (the main taste of these desserts): 4) 'How intense is the flavor of the dessert?'; and 5) 'How intense is the sweetness of the dessert?'. In addition, liking was also asked regarding the overall perception of the dessert: 6) 'How much did you like the dessert?'. Basic demographic questions were also included in the questionnaire.

The participants were asked to rate each question on a 9-point scale labeled at anchors with 'not at all' and 'very much'. Questions 1 to 3 were completed prior to tasting, while the remaining questions were completed during or at the end, to keep the situation as natural for the participants as possible.

After the meal, the questionnaires were collected, the diners paid for their meal as in any normal restaurant and they were thanked for taking part in the study.

The human study reported in this article was performed in accordance with the ethical standards of the Declaration of Helsinki (1964) and approved by the ethical committee of the Institut Paul Bocuse. All procedures were carried out with the adequate understanding and written consent of the participants.

\section{Data analysis}

In order to determine whether the color of the plates exerted a significant effect on the six attributes in question, a three-way ANOVA was performed on the data to examine the meal session (lunch or dinner), the dessert (A, B or C), the plate (white or black) and the interactions as explanatory variables. In addition, two regression analyses were performed to explore the correlation between the ratings of the color intensity, flavor intensity and sweetness intensity, and the correlation between the ratings for appetizing, liking of the presentation (appearance attributes) and overall final liking (post-tasting).

When the effects were significant, honestly significant differences were calculated using Tukey's test. Differences were considered significant when $P \leq 0.05$. Statistical analyses were performed using XLSTAT 2011 (Addinsoft, NY, USA).

\section{Abbreviations}

ANOVA: analysis of variance; M: mean; SD: standard deviation.

\section{Competing interests}

The authors declare that they have no competing interests.

\section{Authors' contributions}

BPF, AG and CS conceived the idea of the study and designed the details. BPF conducted the study and analyzed the data. BPF and CS wrote the manuscript. BPF, AG and CS read and approved the final manuscript.

\section{Acknowledgements}

The authors would like to thank the Ministerio de Educación, Spain, for the grant awarded to BPF. In addition, the authors would like to thank Camille Schwarz, Caroline Jacquier, Rémy Mondon and Alain Dauvergne from Institut Paul Bocuse for their valuable help.

\section{Author details}

${ }^{1}$ Department of Experimental Psychology, University of Oxford, South Parks Road, Oxford OX1 3UD, UK. ${ }^{2}$ Institut Paul Bocuse, Château du Vivier, BP 2569131, Écully Cedex, France.

Received: 10 June 2013 Accepted: 9 August 2013

Published: 23 August 2013

\section{References}

1. Mielby LH, Kildegaard H, Gabrielsen G, Edelenbos M, Thybo AK: Adolescent and adult visual preferences for pictures of fruit and vegetable mixes Effect of complexity. Food Qual Prefer 2012, 26:188-195.

2. Hurling $R$, Shepherd R: Eating with your eyes: effect of appearance on expectations of liking. Appetite 2003, 41:167-174.

3. Zellner DA, Siemers E, Teran V, Conroy R, Lankford M, Agrafiotis A, Ambrose $L$, Locher P: Neatness counts. How plating affects liking for the taste of food. Appetite 2011, 57:642-648.

4. Zellner DA, Lankford M, Ambrose L, Locher P: Art on the plate: Effect of balance and color on attractiveness of, willingness to try and liking for food. Food Qual Prefer 2010, 21:575-578.

5. Marchiori D, Corneille $\mathrm{O}$, Klein $\mathrm{O}$ : Container size influences snack food intake independently of portion size. Appetite 2012, 58:814-817.

6. van Kleef E, Shimizu M, Wansink B: Just a bite: Considerably smaller snack portions satisfy delayed hunger and craving. Food Qual Prefer 2013, 27:96-100.

7. Zellner DA: Contextual influences on liking and preference. Appetite 2007, 49:679-682.

8. Spence $C$, Harrar $V$, Piqueras-Fiszman B: Assessing the impact of the tableware and other contextual variables on multisensory flavour perception. Flavour 2012, 1:7

9. Shankar MU, Levitan CA, Spence C: Grape expectations: the role of cognitive influences in color-flavor interactions. Conscious Cogn 2010, 19:380-390.

10. Spence C: The color of wine - Part 1. The World of Fine Wine 2010, 28:122-129.

11. Verhagen $\mathrm{J}$, Engelen $\mathrm{L}$ : The neurocognitive bases of human multimodal food perception: sensory integration. Neurosci Biobehav Rev 2006, 30:613-650.

12. Spence C, Levitan C, Shankar MU, Zampini M: Does food color influence taste and flavor perception in humans? Chem Percept 2010, 3:68-84.

13. Stevenson RJ: The Psychology of Flavour. Oxford: Oxford University Press; 2009.

14. Guéguen N: The effect of glass color on the evaluation of a beverage's thirst-quenching quality. Curr Psychol Lett Brain Behav Cogn 2003, 11:1-6.

15. Harrar V, Piqueras-Fiszman B, Spence C: There's more to taste in a coloured bowl. Perception 2011, 40:880-882. 
16. Piqueras-Fiszman $B$, Spence $C$ : The influence of the color of the cup on consumers' perception of a hot beverage. J Sensory Stud 2012, 27:324-331.

17. Schifferstein HNJ: The drinking experience: Cup or content? Food Qual Prefer 2009, 20:268-276.

18. Van Ittersum K, Wansink B: Plate size and color suggestibility: The Delboeuf illusion's bias on serving and eating behavior. $J$ Consum Res 2012, 39:215-228.

19. Weintraub DJ, Cooper LA: Coming of age with the Delboeuf illusion: Brightness contrast, cognition, and perceptual development. Developmental Psychol 1972, 6:187-197.

20. Weintraub DJ, Schneck MK: Fragments of Delboeuf and Ebbinghaus illusions: contour/context explorations of misjudged circle size. Percept Psychophys 1986, 40:147-158.

21. Hutchings JB: Food Colour and Appearance. Glasgow: Blackie Academic and Professional; 1994

22. Ekroll V, Faul F, Niederée R: The peculiar nature of simultaneous colour contrast in uniform surrounds. Vision Res 2004, 44:1765-1786.

23. Lyman B: A Psychology of Food: More than a Matter of Taste. New York: Van Nostrand Reinhold; 1989.

24. Piqueras-Fiszman B, Alcaide J, Roura E, Spence $\mathrm{C}$ : Is it the plate or is it the food? Assessing the influence of the color (black or white) and shape of the plate on the perception of the food placed on it. Food Qual Prefer 2012, 24:205-208.

25. Stroebele N, De Castro JM: Effect of ambience on food intake and food choice. Nutrition 2004, 20:821-838.

26. Bell R, Meiselman HL, Pierson BJ, Reeve WG: Effects of adding an Italian theme to a restaurant on perceived ethnicity, acceptability, and selection of foods. Appetite 1994, 22:11-24.

27. de Graaf C, Cardello AV, Kramer FM, Lesher LL, Meiselman HL, Schutz HG: A comparison between liking ratings obtained under laboratory and field conditions: The role of choice. Appetite 2005, 44:15-22.

28. Meiselman HL: Experiencing food products within a physical and social context. In Product Experience. Edited by Schifferstein HNJ, Hekkert P. San Diego, CA: Elsevier; 2008:559-580

29. Rolls BJ, Shide DJ: Both naturalistic and laboratory-based studies contribute to the understanding of human eating behavior. Appetite 1992, 19:76-77.

30. Petit C, Sieffermann JM: Testing consumer preferences for iced-coffee: Does the drinking environment have any influence? Food Qual Prefer 2007, 18:161-172.

31. Hein KA, Hamid N, Jaeger SR, Delahunty CM: Application of a written scenario to evoke a consumption context in a laboratory setting: Effects on hedonic ratings. Food Qual Prefer 2010, 21:410-416.

32. Hein KA, Hamid N, Jaeger SR, Delahunty CM: Effects of evoked consumption contexts on hedonic ratings: A case study with two fruit beverages. Food Qual Prefer 2012, 26:35-44.

33. Zellner DA, Durlach P: Effect of color on expected and experienced refreshment, intensity, and liking of beverages. Am J Psychol 2003, 116:633-647.

34. Churchill A, Meyners M, Griffiths L, Bailey P: The cross-modal effect of fragrance in shampoo: Modifying the perceived feel of both product and hair during and after washing. Food Qual Prefer 2009, 20:320-328.

35. Ariely D: Predictably Irrational: The Hidden Forces that Shape our Decisions. New York: Harper Collins; 2008.

36. Meiselman HL, Johnson JL, Reeve W, Crouch JE: Demonstrations of the influence of the eating environment on food acceptance. Appetite 2000, 35:231-237

37. Spence C, Piqueras-Fiszman B: The Perfect Meal: The Multisensory Science of Food and Dining. Oxford: Wiley-Blackwell. in press.

doi:10.1186/2044-7248-2-24

Cite this article as: Piqueras-Fiszman et al: Assessing the influence of the color of the plate on the perception of a complex food in a restaurant setting. Flavour 2013 2:24.

\section{Submit your next manuscript to BioMed Central and take full advantage of:}

- Convenient online submission

- Thorough peer review

- No space constraints or color figure charges

- Immediate publication on acceptance

- Inclusion in PubMed, CAS, Scopus and Google Scholar

- Research which is freely available for redistribution

Submit your manuscript at www.biomedcentral.com/submit
Biomed Central 